\title{
Vitamin D deficiency is common and is associated with overweight in Mexican children aged 1-11 years
}

\author{
Amada Flores, Mario Flores* , Nayeli Macias, Lucía Hernández-Barrera, Marta Rivera, \\ Alejandra Contreras and Salvador Villalpando \\ Centro de Investigación en Nutrición y Salud, Instituto Nacional de Salud Pública, Avenida Universidad 655, \\ Colonia Santa María Ahuacatitlán, Cuernavaca, Morelos, México, CP 62100
}

Submitted 19 May 2016: Final revision received 11 October 2016: Accepted 17 December 2016: First published online 28 February 2017

\begin{abstract}
Objective: To assess vitamin D dietary sources, intake and 25-hydroxyvitamin D status and their association with individual and sociodemographic characteristics in Mexican children.

Design: Data obtained from 2695 children aged 1-11 years from the Mexican National Health and Nutrition Survey (2012) were analysed. Diet was assessed by a 141-item FFQ. 25-Hydroxyvitamin D was measured by a chemiluminescent assay. Results: Mean vitamin D intake was 3.38 (se 0.09) $\mu \mathrm{g} / \mathrm{d}(135.2$ (se 3.6) IU/d) among pre-school children and 2.85 (SE 0.06) $\mu \mathrm{g} / \mathrm{d}(114.0$ (SE 2.4) IU/d) in school-age children. Milk accounted for $64.4 \%$ of vitamin D intake in pre-school children and $54.7 \%$ in school-age children. Vitamin D deficiency (serum 25-hydroxyvitamin $\mathrm{D}<50 \mathrm{nmol} / \mathrm{l}$ ) was $25.9 \%$ in pre-schoolers and $36.6 \%$ in school-age children. Overweight/obese school-age children had a higher risk of vitamin D deficiency compared with normal-weight children (OR $=2 \cdot 23$; $95 \%$ CI 1.36, 3.66; $P<0.05)$. Conclusions: Vitamin D intakes are low in Mexican children, and milk is the main source of the vitamin. Vitamin D deficiency is common and associated with overweight in school-age children.
\end{abstract}

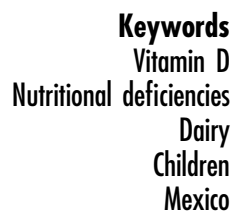

Vitamin D is a prohormone that is essential for Ca absorption and vital for bone development during infancy and childhood. Low serum concentrations of the intermediary metabolite of vitamin $\mathrm{D}$ and the main indicator of vitamin $\mathrm{D}$ nutritional status, 25-hydroxyvitamin D, lead to the release of parathyroid hormone, causing Ca mobilization from bone ${ }^{(1,2)}$. Vitamin D deficiency can cause rickets in children. This is especially negative during the stage in which growth is accelerated $^{(1,2)}$. In addition to its functions in bone metabolism, it has recently been reported that vitamin D may help to reduce the risk of autoimmune diseases, respiratory tract infections, type 1 diabetes and wheezing in childhood ${ }^{(3-5)}$.

The main source of vitamin D is the cutaneous synthesis from 7-dehydrocholesterol in response to sunlight UVB radiation $^{(6)}$. Diet represents a relatively minor source of this prohormone because it is found naturally in only a few foods. Its main dietary sources are milk and dairy, oily fish, and other foods fortified with this vitamin ${ }^{(2,3)}$.

Studies worldwide have shown inadequate vitamin D status for populations of both developed and developing countries $^{(7-11)}$. It is estimated that 1 billion people worldwide have vitamin $\mathrm{D}$ deficiency ${ }^{(7)}$. According to data from the National Health and Nutrition Examination Survey (NHANES) 2003-2006, 10.3\% of children aged 6-18 years in the USA had serum 25-hydroxyvitamin D levels $<40 \mathrm{nmol} / 1$ $(<16 \mathrm{ng} / \mathrm{ml})^{(9)}$. In the same population, another study showed a prevalence of vitamin $\mathrm{D}$ deficiency (serum 25-hydroxyvitamin $\mathrm{D}<50 \mathrm{nmol} / \mathrm{l}(<20 \mathrm{ng} / \mathrm{ml}))$ of 21,29 , 34 and $49 \%$ among healthy weight, overweight, obese and severely obese children, respectively ${ }^{(10)}$.

A study based on data from the Mexican National Health and Nutrition Survey (2006) reported that $24 \%$ of pre-school children were vitamin D-deficient (25-hydroxyvitamin $\mathrm{D}<50 \mathrm{nmol} / \mathrm{l})$ and $30 \%$ of these children showed insufficiency (25-hydroxyvitamin D between 50 and $74.9 \mathrm{nmol} / \mathrm{l})^{(11)}$.

The aim of the present study was to assess dietary sources and intake of vitamin D and 25-hydroxyvitamin D status and their association with individual and sociodemographic characteristics in a representative sample of Mexican children aged 1-11 years.

\section{Methods}

\section{Study population and source of information}

The current cross-sectional study corresponds to a secondary analysis of the Mexican National Health and Nutrition Survey 2012 (ENSANUT-2012). Information from 
1- to 11-year-old Mexican children was used. This specific age group is of particular interest according to national health priorities and therefore funds were obtained for determination of serum 25-hydroxyvitamin $\mathrm{D}$ in this population.

ENSANUT-2012 used a stratified, multistage probability sampling design and constructed sample weights to obtain nationally representative data. Each individual was assigned a sample weight inversely proportional to his/her probability of selection, representing a number of many individuals from the same age/gender/sociodemographic group.

ENSANUT-2012 collected information from 50528 Mexican households through the implementation of 96031 individual questionnaires according to different age groups $^{(12)}$.

\section{Procedures}

\section{Food consumption}

Dietary data were collected using a semi-quantitative FFQ in a sub-sample of the total population of the ENSANUT-2012 (approximately one-sixth of the participants according to the population group). The questionnaire for children aged 1-11 years was applied to their parent or caregiver ${ }^{(13)}$. The FFQ obtained information about foods and beverages classified into fourteen groups. The questions allowed obtaining information about portions, sizes and number of daily servings for each food during the $7 \mathrm{~d}$ preceding the interview $^{(13)}$.

A total of 8195 pre-school and school-age children were evaluated by ENSANUT-2012; this sample is representative of 8327400 children. From this sample, 6827 children had blood samples to evaluate 25-hydroxyvitamin D status. Additionally, a random sample of 1325 pre-school and 1370 school-age children had complete information on dietary intake, anthropometric measures and 25-hydroxyvitamin D determinations. After excluding implausible data, we analysed diet, anthropometry and serum 25-hydroxyvitamin D concentrations from a total sample of 698 pre-school and 956 school-age children.

\section{Anthropometry}

Weight, height and length measurements were done by trained personnel using Lohman and Martorell techniques ${ }^{(14)}$ and standardized according to the methodology proposed by Habicht ${ }^{(15)}$. In children $<2$ years of age, supine position length was measured using a Seca ${ }^{\circledR}$ infantometer with an accuracy of $1 \mathrm{~mm}$. For weight measurement, a Tanita ${ }^{\circledR}$ scale with an accuracy of $100 \mathrm{~g}$ was used, which was calibrated daily. Height was measured using a Dynatop ${ }^{\circledR}$ stadiometer with an accuracy of $1 \mathrm{~mm}$.

\section{Overweight and obesity}

BMI was calculated by dividing weight in kilograms by the square of height in metres. BMI $Z$-score was used according to standards set by the $\mathrm{WHO}^{(16)}$. Children $<5$ years of age were classified as underweight when their $Z$-score was below -2 , scores from -2 to +2 were classified as normal, and scores of more than +2 as overweight. Children aged 5-11 years were classified as low weight when their $Z$-score was below -2 , normal when their $Z$-score was -2 to +1 , and overweight when their $Z$-score was more than +1 to +2 . Those children with $Z$-scores above +2 were classified as obese $^{(16)}$. Underweight children (pre-schoolers, $n$ 13; school age, $n$ 22) were excluded due to the very low numbers in this category.

\section{Socio-economic and demographic data}

A household questionnaire was applied. Among the aspects collected were demographic (gender, age, ethnicity), economic (characteristics of households, property and household appliances) and social data (area of residence and region).

\section{Blood samples}

After an $8 \mathrm{~h}$ fast, a $15 \mathrm{ml}$ blood sample was obtained from the antecubital vein. The sample was centrifuged and separated into individual aliquots, which were transported in nitrogen tanks to the laboratory of the National Institute of Public Health (Instituto Nacional de Salud Pública (INSP); Cuernavaca, Mexico). Samples were stored at $-70^{\circ} \mathrm{C}$ until thawed for analysis.

\section{Laboratory methods}

Serum 25-hydroxyvitamin D was measured with an Abbott Architect ${ }^{\circledR}$ chemiluminescent microparticle immunoassay. Intra- and inter-assay CV were $<10 \%$. This method has shown a high reactivity ( 100\%) with 25-hydroxycholecalciferol (25-hydroxyvitamin $\mathrm{D}_{3}$ ) and an acceptable performance compared with LC/MS/MS $(r=0.73)^{(17)}$. Quality control of measurements in ENSANUT-2012 was performed using the Reference Standard Serum NIST 968E of the National Institute of Standards and Technology, for which it has been established that concentrations of 25-hydroxycholecalciferol are valid using the NIST reference method LCID MS/MS, which is approved by the Joint Committee for Traceability in Laboratory Medicine as a higher-order reference measurement procedure. The accuracy results for this control material were as follows. NIST 968E L1: mean $7 \cdot 1(\mathrm{sD} 0 \cdot 2) \mathrm{ng} / \mathrm{ml}, \mathrm{CV}=2 \cdot 2 \%$ (reference value: $7 \cdot 1$ (SD 0.1) $\mathrm{ng} / \mathrm{ml}$ ); NIST 968E L3: mean 19.9 (SD 1.4) ng/ml, CV $\%=6.9 \%$ (reference value: $19.9(\mathrm{sD} 0.4) \mathrm{ng} / \mathrm{ml})$. Also, during the analysis of samples, three quality controls available from Abbott (Batch 03912A000) were used with the following results. LOW LEVEL: mean 19.5 (SD 1.5$) \mathrm{ng} / \mathrm{ml}, \mathrm{CV}=7.6 \%$ (reference value: 20 (sD 7) $\mathrm{ng} / \mathrm{ml}$ ); INTERMEDIATE LEVEL: mean 39.5 ( $\mathrm{SD} 2.3$ ) $\mathrm{ng} / \mathrm{ml}, \mathrm{CV}=5.9 \%$ (reference value: 40 (sD 14) ng/ml); HIGH LEVEL: mean 75.6 (sD 3.3) ng/ml, $\mathrm{CV}=4 \cdot 4 \%$ (reference value: $75(\mathrm{SD} 26) \mathrm{ng} / \mathrm{ml})$. 


\section{Variables}

Dietary sources

Dietary sources of vitamin D were identified according to the food composition table compiled and updated by the INSP $^{(18)}$. Vitamin D content is presented per $100 \mathrm{~g}$ or $100 \mathrm{ml}$ of food. Procedures for calculating daily energy and nutrient intakes have been previously described ${ }^{(13)}$. We identified the foods with the highest contribution to vitamin D intake in Mexican children. In accordance with Institute of Medicine recommendations, a vitamin D intake of $\geq 10 \mu \mathrm{g} / \mathrm{d}$ ( $\geq 400 \mathrm{IU} / \mathrm{d}$ ) was considered adequate ${ }^{(2)}$.

\section{Vitamin D status}

Serum 25-hydroxyvitamin D concentrations were used to evaluate vitamin D status. Vitamin D deficiency was defined as serum 25-hydroxyvitamin $\mathrm{D}<50 \mathrm{nmol} / \mathrm{l}$ $(<20 \mathrm{ng} / \mathrm{ml})^{(1,19,20)}$.

\section{Socio-economic region}

For sampling and analytical purposes of ENSANUT-2012, the regions in the country were divided as follows: North (Baja California, Baja California Sur, Coahuila, Chihuahua, Durango, Nuevo Leon, Sonora, Tamaulipas), Mexico City (Federal District), Central (Aguascalientes, Colima, Mexico, Guanajuato, Jalisco, Michoacán, Morelos, Nayarit, Querétaro, San Luis Potosí, Sinaloa, Zacatecas) and South (Campeche, Chiapas, Guerrero, Hidalgo, Oaxaca, Puebla, Quintana Roo, Tabasco, Tlaxcala, Veracruz, Yucatán) ${ }^{(21)}$.

\section{Urban and rural areas}

Urban localities were defined as those with a population of $\geq 2500$ inhabitants; rural localities were defined as those areas with $<2500$ inhabitants $^{(21)}$.

\section{Socio-economic status}

A socio-economic status index was constructed using principal component analysis on housing characteristics and availability of household goods. The first component explained $40.5 \%$ of the total variability with a $\lambda$ value of 3.24 and was selected as the index, which was later divided in tertiles (low, medium and high socio-economic status).

\section{Ethnicity}

The mother or caregiver was asked if the child spoke an indigenous language. If the answer was 'yes', the child was considered as 'indigenous ${ }^{\text {,21) }}$ (only for children aged 3 years or above).

\section{Statistical analysis}

We carried out a descriptive analysis presented as means and their standard errors for continuous variables and simple tabulations for categorical variables. Multivariate logistic regression models were used to evaluate the association between vitamin D deficiency and individual and sociodemographic characteristics. An expansion factor was applied to all statistical calculations to maintain representativeness, according to the survey's complex design. The SVY module in the Stata statistical software package version 12.0 was used to adjust for the complex survey design. A significance level of 0.05 was used in all analyses.

\section{Ethical considerations}

The ENSANUT-2012 was approved by the INSP Committees on Ethics and Biosafety and by the Research Committee of INSP. Children's assent was obtained for children aged 6 years or older. Informed consent of parents or guardians was also obtained for participation in the study ${ }^{(12)}$.

\section{Results}

All results are presented stratified for pre-school (1-4 years) and school-age (5-11 years) children. Data from 1325 children aged $1-4$ years and 1370 children aged 5-11 years who participated in ENSANUT-2012 and had complete information on dietary intake and anthropometric measures were analysed, representing 8.7 million pre-school children and 15.8 million school-age children, respectively, in accordance with the sample weights used. The proportions of pre-schoolers and school-age children that formed the study sample and gender distribution in both groups are shown in Table 1 . In relation to nutritional status, we observed that $91 \%$ of pre-school children had a normal BMI, whereas the remaining 9\% were overweight. Among school-age children, 65\% had a normal BMI, whereas the prevalence of overweight and obesity was 20 and $15 \%$, respectively.

Percentage contribution to vitamin D intake by food group is shown in Table 2. Dairy, milk, and milk-based beverages and desserts accounted for $90 \%$ of vitamin D intake among pre-school children and $85 \%$ among schoolage children. Fish, meat, eggs and other animal-origin products contributed $\approx 20 \%$ to total vitamin $D$ intake in school-age children.

Children aged $1-4$ years had a vitamin $D$ intake of $3.38 \mu \mathrm{g} / \mathrm{d}(135 \cdot 2 \mathrm{IU} / \mathrm{d})$, while mean vitamin D intake was $2 \cdot 85 \mu \mathrm{g} / \mathrm{d}(114.0 \mathrm{IU} / \mathrm{d})$ in school-age children (Table 3$)$. For both age groups, intakes were higher among overweight/obese children compared with normal-weight children. Vitamin D intakes were higher among urban compared with rural children and for children who lived in Mexico City compared with children from other regions. Vitamin D intake was positively associated with socioeconomic status and the lowest intakes were observed among indigenous children. Only $1.5 \%$ of pre-schoolers and $2.3 \%$ of school-age children consumed a supplement containing vitamin D.

Vitamin D status is presented for 698 pre-school children who had dietary information, representing 2.7 million pre-school children nationwide, and 956 school-age 
Table 1 General characteristics of Mexican children aged 1-11 years, Mexican National Health and Nutrition Survey 2012 (ENSANUT-2012)

\begin{tabular}{|c|c|c|c|c|c|c|c|c|}
\hline \multirow[b]{2}{*}{ Variable } & \multicolumn{4}{|c|}{ Pre-school children (1-4 years) } & \multicolumn{4}{|c|}{ School-age children (5-11 years) } \\
\hline & $\begin{array}{c}\text { Sub-category or } \\
\text { value }\end{array}$ & $n$ & $\begin{array}{l}n \text { expanded } \\
\text { (thousands) }\end{array}$ & $\begin{array}{c}\% \\
\text { expanded }\end{array}$ & $\begin{array}{l}\text { Sub-category or } \\
\text { value }\end{array}$ & $n$ & $\begin{array}{l}n \text { expanded } \\
\text { (thousands) }\end{array}$ & $\begin{array}{c}\% \\
\text { expanded }\end{array}$ \\
\hline \multirow{6}{*}{$\begin{array}{l}\text { Age (years) } \\
\text { Mean } \\
\text { SE } \\
95 \% \mathrm{Cl}\end{array}$} & $1-4$ & 1325 & $8744 \S$ & $100 \cdot 0$ & $5-11$ & 1370 & $15838 \S$ & $100 \cdot 0$ \\
\hline & $3 \cdot 0$ & & & & $8 \cdot 7$ & & & \\
\hline & 0.0 & & & & & & & \\
\hline & $2 \cdot 9,3 \cdot 1$ & & & & $8.5,8.8$ & & & \\
\hline & $1-2$ & 656 & 4286 & $49 \cdot 0$ & $5-8$ & 608 & 8746 & $55 \cdot 0$ \\
\hline & $3-4$ & 669 & 4458 & $51 \cdot 0$ & $9-11$ & 762 & 7091 & $45 \cdot 0$ \\
\hline \multicolumn{9}{|l|}{ Sex } \\
\hline Male & & 620 & 4432 & 51.0 & & 716 & 8060 & 51.0 \\
\hline Female & & 705 & 4311 & $49 \cdot 0$ & & 654 & 7777 & $49 \cdot 0$ \\
\hline \multirow[t]{4}{*}{ BMI† } & n 1241 & & 8089 & & $n 1300$ & & 14952 & \\
\hline & Normal & 1123 & 7387 & $91 \cdot 3$ & Normal & 827 & 9648 & 64.5 \\
\hline & Overweight & 118 & 701 & 8.7 & Overweight & 259 & 3069 & 20.5 \\
\hline \multirow{2}{*}{\multicolumn{9}{|c|}{ Area }} \\
\hline & & & & & & & & \\
\hline Rural & & 525 & 2619 & $30 \cdot 0$ & & 500 & 4658 & $29 \cdot 4$ \\
\hline Urban & & 800 & 6124 & $70 \cdot 0$ & & 870 & 11179 & $70 \cdot 6$ \\
\hline \multicolumn{9}{|l|}{ Region } \\
\hline North & & 260 & 1721 & $19 \cdot 7$ & & 290 & 3019 & $19 \cdot 1$ \\
\hline Central & & 468 & 2766 & 31.6 & & 478 & 4923 & $31 \cdot 1$ \\
\hline Mexico City & & 74 & 1370 & $15 \cdot 7$ & & 112 & 2555 & $16 \cdot 1$ \\
\hline South & & 523 & 2885 & 33.0 & & 490 & 5339 & 33.7 \\
\hline Ethnicity $\ddagger$ & $n 633$ & & 4252 & & $n 966$ & & 10844 & \\
\hline Indigenous & & 42 & 199 & 4.7 & & 63 & 693 & $6 \cdot 4$ \\
\hline Non-indigenous & & 591 & 4052 & $95 \cdot 3$ & & 903 & 10151 & 93.6 \\
\hline \multicolumn{9}{|l|}{$\begin{array}{l}\text { Socio-economic } \\
\text { status }\end{array}$} \\
\hline Low & & 568 & 3333 & $38 \cdot 1$ & & 517 & 5287 & $33 \cdot 4$ \\
\hline Medium & & 420 & 2694 & $30 \cdot 8$ & & 468 & 5185 & 32.7 \\
\hline High & & 337 & 2716 & $31 \cdot 1$ & & 385 & 5365 & 33.9 \\
\hline
\end{tabular}

†Cut-off points of BMI Z-score according to WHO.

IInformation on ethnicity is available for families with children $>3$ years old.

$\S$ According to Census data (2010) and population projections, the total Mexican population aged 1-4 years was 8.9 million and aged 5-11 years was 15.8 million, in $2012^{(27)}$.

Table 2 Dietary sources, mean intake and percentage contribution to vitamin D intake in Mexican children aged 1-11 years, Mexican National Health and Nutrition Survey 2012 (ENSANUT-2012)

\begin{tabular}{|c|c|c|c|c|c|c|}
\hline \multirow[b]{3}{*}{ Food group } & \multicolumn{3}{|c|}{$\begin{array}{l}\text { Pre-school children } \\
\quad(1-4 \text { years }) \dagger\end{array}$} & \multicolumn{3}{|c|}{$\begin{array}{l}\text { School-age children } \\
\quad(5-11 \text { years }) \ddagger\end{array}$} \\
\hline & \multicolumn{2}{|c|}{ Intake $(I U / d) \S$} & \multirow[b]{2}{*}{$\%$ contribution $\|$} & \multicolumn{2}{|c|}{ Intake (IU/d)§ } & \multirow[b]{2}{*}{$\%$ contribution| } \\
\hline & Mean & SE & & Mean & SE & \\
\hline Milk & $110 \cdot 9$ & $3 \cdot 1$ & 64.4 & $80 \cdot 9$ & 2.5 & $54 \cdot 7$ \\
\hline Dairy, cheese, yoghurt & $19 \cdot 4$ & $1 \cdot 0$ & $13 \cdot 4$ & $15 \cdot 9$ & $1 \cdot 1$ & $10 \cdot 4$ \\
\hline Milk-based beverages (atoles) & $8 \cdot 0$ & 0.7 & $6 \cdot 6$ & $17 \cdot 3$ & 1.7 & $14 \cdot 0$ \\
\hline Milk-based desserts: flan, Jell-O, pie, ice cream, cake & $7 \cdot 1$ & 0.4 & $6 \cdot 0$ & $6 \cdot 6$ & 0.4 & $6 \cdot 0$ \\
\hline Chicken, meat and eggs & $17 \cdot 5$ & 0.6 & $19 \cdot 4$ & $20 \cdot 1$ & 0.6 & $22 \cdot 0$ \\
\hline Fish, tuna and sardine & $9 \cdot 7$ & 0.8 & $8 \cdot 8$ & $14 \cdot 7$ & $1 \cdot 1$ & $14 \cdot 3$ \\
\hline Ready-to eat cereals, corn, rice, doughnuts, cookies, sweets, cupcakes & $12 \cdot 8$ & $1 \cdot 0$ & $8 \cdot 1$ & $17 \cdot 3$ & 0.9 & $12 \cdot 3$ \\
\hline Mexican antojitos, sandwiches, hamburgers, hot dogs & 2.5 & 0.1 & $2 \cdot 1$ & $4 \cdot 8$ & 0.2 & $5 \cdot 1$ \\
\hline Cream, mayonnaise, margarine, butter, lard & $2 \cdot 3$ & 0.2 & $2 \cdot 0$ & $2 \cdot 7$ & 0.1 & $2 \cdot 6$ \\
\hline Other (fried beans, vegetables) & 0.8 & 0.2 & 1.0 & 0.8 & 0.9 & $1 \cdot 2$ \\
\hline
\end{tabular}

†n 1235; $n$ expanded 8744340.

$\ddagger n$ 1370; $n$ expanded 15838145 .

$\S$ To convert to $\mu \mathrm{g} / \mathrm{d}$, divide IU/d value by 40 .

|| Percentage contributions not necessarily add to $100 \%$, given that they refer to groups' averages.

children, representing 4.6 million nationwide (Table 4). Mean serum 25-hydroxyvitamin D among pre-schoolers was $60 \cdot 3(95 \%$ CI 57.8, 62.7) $\mathrm{nmol} / \mathrm{l}$ and 56.6 (95\% CI 55.2, 58.0) $\mathrm{nmol} / \mathrm{l}$ in school-age children. Vitamin D deficiency was observed in $25.9 \%$ of pre-schoolers and $36.6 \%$ of schoolage children. Higher prevalence of vitamin D deficiency was observed among older children (9-11 years), school-age girls and overweight/obese school-age children. Among 
Table 3 Vitamin D intake according to general characteristics of Mexican children aged 1-11 years, Mexican National Health and Nutrition Survey 2012 (ENSANUT-2012)

\begin{tabular}{|c|c|c|c|c|c|c|c|}
\hline \multirow[b]{3}{*}{ Variable } & \multirow{2}{*}{\multicolumn{3}{|c|}{$\frac{\text { Pre-school children (1-4 years) } \dagger}{\text { Intake }(\mathrm{IU} / \mathrm{d}) \S}$}} & & \multicolumn{3}{|c|}{ School-age children (5-11 years) $\ddagger$} \\
\hline & & & & & \multicolumn{3}{|c|}{ Intake (IU/d)§ } \\
\hline & Mean & SE & $95 \% \mathrm{Cl}$ & & Mean & $\mathrm{SE}$ & $95 \% \mathrm{Cl}$ \\
\hline Total & $135 \cdot 2$ & 3.6 & $128 \cdot 5,141 \cdot 8$ & & 114.0 & $2 \cdot 4$ & $108.9,118.9$ \\
\hline \multicolumn{8}{|l|}{ Age (years) } \\
\hline $1-2$ & $130 \cdot 8$ & $4 \cdot 8$ & $121 \cdot 3,140 \cdot 2$ & $5-8$ & $120 \cdot 2^{b}$ & 3.8 & $112 \cdot 6,127 \cdot 7$ \\
\hline $3-4$ & $139 \cdot 4$ & 4.7 & $130 \cdot 2,148 \cdot 7$ & $9-11$ & $106 \cdot 1^{a}$ & $3 \cdot 1$ & $100 \cdot 0,112 \cdot 2$ \\
\hline \multicolumn{8}{|l|}{ Sex } \\
\hline Male & $136 \cdot 3$ & $5 \cdot 0$ & $126 \cdot 4,146 \cdot 2$ & & 112.9 & 3.5 & $106.0,119.8$ \\
\hline Female & $134 \cdot 0$ & 4.2 & $126 \cdot 0,142 \cdot 2$ & & 114.9 & 3.9 & $107 \cdot 3,122.5$ \\
\hline \multicolumn{8}{|l|}{ BMI } \\
\hline$n 1241$ & & & & $n 1300$ & & & \\
\hline Normal & $133 \cdot 1^{\mathrm{b}}$ & $3 \cdot 8$ & $125 \cdot 5,140 \cdot 6$ & Normal & $110 \cdot 4^{b}$ & 3.3 & $104 \cdot 0,116 \cdot 8$ \\
\hline Overweight & $159 \cdot 9^{a}$ & $7 \cdot 3$ & $145 \cdot 6,174 \cdot 2$ & Overweight/obesity & $119.1^{\mathrm{a}}$ & $4 \cdot 1$ & $111 \cdot 1,127 \cdot 1$ \\
\hline \multicolumn{8}{|l|}{ Area } \\
\hline Urban & $145 \cdot 6^{\mathrm{b}}$ & 4.3 & $137 \cdot 2,154 \cdot 0$ & & $125 \cdot 0^{\mathrm{b}}$ & $3 \cdot 2$ & $118 \cdot 8,131 \cdot 2$ \\
\hline Rural & $110 \cdot 9^{\mathrm{a}}$ & 4.9 & $101 \cdot 2,120.5$ & & $87 \cdot 2^{\mathrm{a}}$ & 3.9 & $79.4,95.0$ \\
\hline \multicolumn{8}{|l|}{ Region } \\
\hline North & $154 \cdot 4^{d}$ & $6 \cdot 0$ & $142 \cdot 7,166 \cdot 2$ & & $129 \cdot 1^{\mathrm{c}, \mathrm{d}}$ & $5 \cdot 8$ & $117 \cdot 7,140 \cdot 4$ \\
\hline Central & $138 \cdot 4^{d}$ & $5 \cdot 6$ & $127.4,149.5$ & & $117 \cdot 5^{\mathrm{c}, \mathrm{d}}$ & 4.3 & $109 \cdot 1,126 \cdot 0$ \\
\hline Mexico City & $156 \cdot 6^{\mathrm{d}}$ & $13 \cdot 2$ & $130 \cdot 7,182 \cdot 5$ & & $148 \cdot 0^{\mathrm{a}, \mathrm{b}, \mathrm{d}}$ & 6.4 & $135 \cdot 1,160.3$ \\
\hline South & $110 \cdot 4^{\mathrm{a}, \mathrm{b}}$ & $4 \cdot 8$ & $101 \cdot 0,119 \cdot 8$ & & $85 \cdot 7^{\mathrm{a}, \mathrm{b}, \mathrm{c}}$ & 4.2 & $77.6,93.9$ \\
\hline \multicolumn{8}{|l|}{ Ethnicity } \\
\hline \multicolumn{8}{|l|}{$n 633$} \\
\hline Indigenous & $40 \cdot 9^{b}$ & $5 \cdot 8$ & $29 \cdot 4,52 \cdot 4$ & & $45 \cdot 0^{b}$ & 4.6 & $36 \cdot 0,54 \cdot 0$ \\
\hline Non-indigenous & $145 \cdot 1^{\mathrm{a}}$ & $5 \cdot 0$ & $135 \cdot 3,155 \cdot 0$ & & $117 \cdot 8^{\mathrm{a}}$ & $2 \cdot 6$ & $112 \cdot 7,123.0$ \\
\hline \multicolumn{8}{|c|}{ Socio-economic status } \\
\hline Low & $110 \cdot 9^{b, c}$ & 4.7 & $101 \cdot 6,120 \cdot 2$ & & $82 \cdot 2^{b, c}$ & 4.0 & $74.4,90 \cdot 0$ \\
\hline Medium & $138 \cdot 5^{\mathrm{a}, \mathrm{c}}$ & 5.9 & $127 \cdot 0,150 \cdot 0$ & & $116 \cdot 1^{\mathrm{a}, \mathrm{c}}$ & 4.1 & $108 \cdot 0,124.2$ \\
\hline High & $161 \cdot 7^{a, b}$ & 6.9 & $148 \cdot 2,175 \cdot 2$ & & $143 \cdot 0^{a}$ & $4 \cdot 3$ & $134.4,151.5$ \\
\hline
\end{tabular}

a,b,c,d Mean values within a column with unlike superscript letters were significantly different $(P<0.05)$. †n 1325; $n$ expanded 8744340

$\ddagger n$ 1370; $n$ expanded 15838145

$\S$ To convert to $\mu \mathrm{g} / \mathrm{d}$, divide IU/d value by 40 .

school-age children, a higher prevalence of vitamin D deficiency was observed in urban children, those from the Central region, indigenous children and those with higher socio-economic status. Vitamin D status for the whole sample of 6827 children - with or without dietary data - is presented in the online supplementary material, Supplemental Table 1. This number is representative of $24 \cdot 1$ million Mexican children. In multivariate, logistic regression analysis, vitamin $\mathrm{D}$ deficiency was positively associated with age, female gender, overweight/obesity and living in the Central region. The analysis showed no statistically significant associations among pre-schoolers (Table 5).

\section{Discussion}

The present nationally representative study showed that vitamin D intakes are low in Mexican children aged 1-11 years, and milk and dairy are the main sources of the vitamin. Moreover, vitamin D deficiency is common, affecting $26 \%$ of pre-schoolers and $~ 37 \%$ of school-age children in Mexico.

A recent review on vitamin D status in Latin America and the Caribbean found that vitamin D intakes in children and adolescents were between 1.80 and $4.63 \mu \mathrm{g} / \mathrm{d}$ (72 and $185 \cdot 2 \mathrm{IU} / \mathrm{d})^{(8)}$. This was associated with a prevalence of dietary inadequacy of $100 \%$. The same review showed that vitamin $\mathrm{D}$ deficiency (25-hydroxyvitamin $\mathrm{D}<50$ nmol/l) affected 8 to $27 \%$ of children and adolescents ${ }^{(8)}$. Our data are in accordance with the aforementioned study, confirming that vitamin D intake is insufficient and that vitamin D deficiency is a public health problem in Latin America.

A previous study, from the 2006 Mexican National Health and Nutrition Survey ${ }^{(11)}$, reported a prevalence of vitamin $\mathrm{D}$ deficiency of $16 \%$ among children aged 2-12 years. This is half of the prevalence currently observed. While this difference could be explained in part by lifestyle changes (i.e. decreased outdoor activities due social distress in some areas, increased use of sunscreen), aspects related to the laboratory analytical technique and handling of the serum samples in the previous survey should be also considered. The higher accuracy of the actual estimations, as reflected by smaller SD, the larger sample size and the use of NIST materials warrant a better estimation in the current survey.

In our study, overweight and obese children had a higher prevalence of vitamin D deficiency compared with 
Table 4 Serum 25-hydroxyvitamin D status according to general characteristics of Mexican children aged 1-11 years, Mexican National Health and Nutrition Survey 2012 (ENSANUT-2012)

\begin{tabular}{|c|c|c|c|c|c|c|c|c|c|c|c|c|c|}
\hline \multirow[b]{3}{*}{ Variable } & \multicolumn{6}{|c|}{ Pre-school children (1-4 years) $\dagger$} & & \multicolumn{6}{|c|}{ School-age children (5-11 years) $\ddagger$} \\
\hline & \multicolumn{6}{|c|}{ 25-Hydroxyvitamin D (nmol/l) } & & \multicolumn{6}{|c|}{ 25-Hydroxyvitamin D (nmol/l) } \\
\hline & Mean & $95 \% \mathrm{Cl}$ & $<50 \mathrm{nmol} / /(\%)$ & $95 \% \mathrm{Cl}$ & $\geq 50 \mathrm{nmol} / /(\%)$ & $95 \% \mathrm{Cl}$ & & Mean & $95 \% \mathrm{Cl}$ & $<50 \mathrm{nmol} / /(\%)$ & $95 \% \mathrm{Cl}$ & $\geq 50 \mathrm{nmol} / \mathrm{l}(\%)$ & $95 \% \mathrm{Cl}$ \\
\hline $1-2$ & $61 \cdot 0$ & $57 \cdot 4,64 \cdot 5$ & 24.6 & $17.5,33.3$ & $75 \cdot 4$ & $66 \cdot 7,82 \cdot 5$ & $5-8$ & $58 \cdot 3$ & $56 \cdot 3,60 \cdot 2$ & 32.8 & $25 \cdot 7,40 \cdot 8$ & $67 \cdot 2$ & $59 \cdot 2,74 \cdot 3$ \\
\hline $3-4$ & 59.6 & $56 \cdot 8,62 \cdot 4$ & 27.3 & $20 \cdot 2,35 \cdot 8$ & 72.7 & $64 \cdot 2,79 \cdot 8$ & $9-11$ & $54 \cdot 3$ & $52 \cdot 5,56 \cdot 2$ & 41.7 & $34.9,48.9$ & 58.2 & $51 \cdot 1,65 \cdot 0$ \\
\hline \multicolumn{14}{|c|}{ 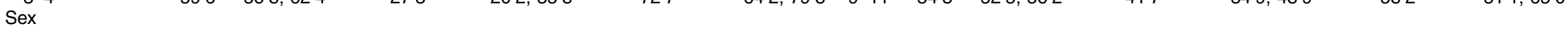 } \\
\hline Male & $61 \cdot 4$ & $57 \cdot 5,65 \cdot 4$ & 24.6 & $17 \cdot 6,33 \cdot 3$ & 75.4 & $66 \cdot 7,82 \cdot 4$ & & 58.4 & $56 \cdot 4,60 \cdot 4$ & $29.1^{*}$ & $22 \cdot 9,36 \cdot 2$ & 70.9 & $63.8,77 \cdot 1$ \\
\hline \multicolumn{14}{|l|}{ BMI } \\
\hline $\begin{array}{l}\text { Normal } \\
\text { Overweight }\end{array}$ & $\begin{array}{l}60.5 \\
59.0\end{array}$ & $\begin{array}{l}51.8,63.1 \\
52 \cdot 6,65 \cdot 5\end{array}$ & $\begin{array}{l}28.1 \\
28.7\end{array}$ & $\begin{array}{l}20.2,31.9 \\
13 \cdot 7,50.5\end{array}$ & $\begin{array}{l}71.3 \\
71.3\end{array}$ & $49.5,86.3$ & & $\begin{array}{l}58 \cdot 1 \\
55.1\end{array}$ & $\begin{array}{l}56 \cdot 3,59 \cdot 8 \\
52 \cdot 4,57 \cdot 8\end{array}$ & 47.7 & $\begin{array}{l}24 \cdot 1,35 \cdot 1 \\
38 \cdot 5,57 \cdot 0\end{array}$ & $\begin{array}{l}10.5 \\
52 \cdot 3\end{array}$ & $\begin{array}{l}64 \cdot 3,75 \cdot 9 \\
43 \cdot 0,61 \cdot 5\end{array}$ \\
\hline \multirow{2}{*}{\multicolumn{14}{|c|}{ Area }} \\
\hline & & & & & & & & & & & & & \\
\hline Rural & 60.5 & $58 \cdot 3,63 \cdot 0$ & $25 \cdot 1$ & $19 \cdot 6,31.5$ & 74.9 & $68 \cdot 4,80 \cdot 4$ & & $58 \cdot 0$ & $55 \cdot 1,60 \cdot 6$ & 33.5 & $26 \cdot 1,41 \cdot 9$ & 66.5 & $58 \cdot 1,73.9$ \\
\hline Urban & $60 \cdot 2$ & $57 \cdot 0,63 \cdot 4$ & 26.2 & $19 \cdot 6,34 \cdot 2$ & 73.8 & $65.8,80 \cdot 4$ & & 56.2 & $55 \cdot 1,60.6$ & 37.6 & $31.5,44.2$ & 62.4 & $55.8,68.5$ \\
\hline \multicolumn{14}{|l|}{ Region } \\
\hline North & 55.5 & $52 \cdot 0,59 \cdot 1$ & 29.4 & $18 \cdot 9,42 \cdot 8$ & $70 \cdot 6$ & $57 \cdot 2,81 \cdot 1$ & & 59.0 & $56 \cdot 0,62 \cdot 0$ & 31.4 & $22 \cdot 5,41 \cdot 8$ & 68.6 & $58 \cdot 2,77.5$ \\
\hline Central & 61.4 & $57.4,65.5$ & 25.8 & $17 \cdot 9,35.7$ & 74.2 & $64 \cdot 3,82 \cdot 1$ & & 54.0 & $61 \cdot 3,57 \cdot 0$ & $45 \cdot 2^{*}$ & $36 \cdot 8,53 \cdot 8$ & 54.8 & $46 \cdot 2,63 \cdot 2$ \\
\hline Mexico City & 59.0 & $49.5,68.0$ & 31.8 & $15 \cdot 3,54 \cdot 6$ & 68.2 & $45.4,84.7$ & & 56.0 & $53.0,59.0$ & 37.8 & $25 \cdot 5,52 \cdot 0$ & 62.2 & $48.0,74.5$ \\
\hline \multicolumn{14}{|l|}{$\begin{array}{l}\text { Ethnicity§ } \\
\text { n } 359\end{array}$} \\
\hline \multicolumn{14}{|c|}{ Socio-economic status } \\
\hline Low & $61 \cdot 1$ & $59 \cdot 2,63 \cdot 0$ & $22 \cdot 3$ & $17 \cdot 2,28 \cdot 3$ & 77.7 & $71 \cdot 7,82 \cdot 7$ & & $60 \cdot 1$ & $57 \cdot 2,63 \cdot 0$ & 30.6 & $23 \cdot 7,38.5$ & 69.4 & $61 \cdot 5,76 \cdot 3$ \\
\hline Medium & $57 \cdot 3$ & $54 \cdot 6,60 \cdot 0$ & 30.9 & $21 \cdot 3,42 \cdot 5$ & 69.1 & $57 \cdot 5,78 \cdot 7$ & & 55.5 & $53 \cdot 2,58 \cdot 0$ & 35.4 & $27 \cdot 1,44 \cdot 8$ & 64.5 & $55 \cdot 2,72 \cdot 9$ \\
\hline High & $62 \cdot 4$ & $55 \cdot 0,70.0$ & $26 \cdot 1$ & $14 \cdot 6,42 \cdot 1$ & 73.9 & $57 \cdot 9,85 \cdot 4$ & & 54.7 & $52 \cdot 7,57 \cdot 0$ & 42.6 & $32 \cdot 9,53 \cdot 0$ & 57.4 & $47 \cdot 0,67 \cdot 1$ \\
\hline
\end{tabular}

*Among school-age children, prevalence of vitamin $\mathrm{D}$ deficiency (serum 25 -hydroxyvitamin $\mathrm{D}<50 \mathrm{nmol} / \mathrm{l}(<20 \mathrm{ng} / \mathrm{ml})$ ) was significantly different among males $v$. females, normal weight $v$. overweight and Cental $v$. South $(P<0.05)$

tn 698; $n$ expanded 2692583.

tn 956; $n$ expanded 4654316 .

$\S$ Ethnicity information is available for children $>3$ years of age. 
Table 5 Risk of vitamin D deficiency† in Mexican children aged 1-11 years, Mexican National Health and Nutrition Survey 2012 (ENSANUT-2012)

\begin{tabular}{|c|c|c|c|c|c|}
\hline \multirow[b]{2}{*}{ Variable } & \multicolumn{2}{|c|}{$\begin{array}{l}\text { Pre-school children } \\
\text { (1-4 years) }\end{array}$} & & \multicolumn{2}{|c|}{$\begin{array}{l}\text { School-age children } \\
\quad(5-11 \text { years })\end{array}$} \\
\hline & OR & $95 \% \mathrm{Cl}$ & & OR & $95 \% \mathrm{Cl}$ \\
\hline \multicolumn{6}{|l|}{ Age (years) } \\
\hline $1-2$ & 1.00 & Ref. & $5-8$ & 1.00 & Ref. \\
\hline $3-4$ & 1.24 & $0.40,3.87$ & $9-11$ & $1.76^{\star}$ & $1.20,2.57$ \\
\hline \multicolumn{6}{|l|}{ Sex } \\
\hline Male & 1.00 & Ref. & & 1.00 & Ref. \\
\hline Female & 1.09 & $0.61,1.93$ & & $1.63^{\star}$ & $1 \cdot 12,2 \cdot 39$ \\
\hline \multicolumn{6}{|l|}{ BMI } \\
\hline Normal & 1.00 & Ref. & Normal & 1.00 & Ref. \\
\hline Overweight & 1.08 & $0.40,2.96$ & Overweight/obesity & $2 \cdot 23^{*}$ & $1.36,3.66$ \\
\hline \multicolumn{6}{|l|}{ Area } \\
\hline Urban & 1.00 & Ref. & & 1.00 & Ref. \\
\hline Rural & 1.35 & $0.76,2.38$ & & 0.83 & $0.53,1.29$ \\
\hline \multicolumn{6}{|l|}{ Region } \\
\hline North & 1.00 & Ref. & & 1.00 & Ref. \\
\hline Central & 0.81 & $0.37,1.79$ & & $2 \cdot 18^{\star}$ & $1.31,3.63$ \\
\hline Mexico City & 1.21 & $0.37,3.42$ & & 1.57 & $0.81,3.06$ \\
\hline South & 0.65 & $0.32,1.34$ & & 1.09 & $0.65,1.80$ \\
\hline \multicolumn{6}{|l|}{ Ethnicity } \\
\hline Indigenous & 1.00 & Ref. & & 1.00 & Ref. \\
\hline Non-indigenous & 0.93 & $0.54,1.62$ & & $0.45^{\star}$ & $0.22,0.92$ \\
\hline \multicolumn{6}{|l|}{ Socio-economic status } \\
\hline Low & 1.00 & Ref. & & 1.00 & Ref. \\
\hline Medium & 1.45 & $0.73,2.66$ & & 1.08 & $0.67,1.74$ \\
\hline High & 1.18 & $0.49,2.81$ & & $1.62^{\star}$ & $0.98,2.67$ \\
\hline Energy (kcal/d) & 1.00 & $0.99,1.00$ & & 0.99 & $0.99,1.00$ \\
\hline Vitamin D intake (IU/d) & 1.00 & $0.99,1.00$ & & 0.99 & $0.99,1.00$ \\
\hline
\end{tabular}

normal-weight children. The positive association of BMI with higher odds of vitamin D deficiency has been previously reported in the $\mathrm{USA}^{(10)}$ and Mexico ${ }^{(11)}$. Sequestration of 25-hydroxyvitamin $\mathrm{D}$ in adipose tissue and abnormalities in vitamin $\mathrm{D}$ metabolism are plausible mechanisms behind this association ${ }^{(22,23)}$.

Using data from NHANES 2003-2006, Karalius et al. found that the prevalence of vitamin D (25-hydroxyvitamin D) concentrations below $50 \mathrm{nmol} / 1$ was between $10 \cdot 8$ and $24.8 \%$ in children aged 6-18 years ${ }^{(9)}$. It is noticeable that vitamin D deficiency is higher in Mexican children than in American children. One would expect, since occasional sun exposure is the main source of circulating 25-hydroxyvitamin D, that serum concentrations should be higher in Mexico than in the USA. Despite our belief that Mexican children are not having enough sun exposure and that dietary vitamin D intakes could be lower in Mexican compared with US children, the increased use of vitamin D-containing supplements in the US population could be an explanation for this somehow counter-intuitive finding. In a nationally representative sample of children aged 1-11 years from the USA, Mansbach et $\mathrm{al}^{(24)}$ found that $\sim 34 \%$ of the children consumed a vitamin D supplement and that this had a positive effect on 25-hydroxyvitamin D concentrations and the prevalence of vitamin D deficiency. In the present study, we found that only $\sim 2 \%$ of children consumed a vitamin D-containing supplement. Moreover, we did not find a difference in serum 25-hydroxyvitamin D concentrations between children who consumed a vitamin D-containing supplement and those who did not, indicating either that consumption occurred on a non-regular basis or that the dose was not sufficient to cause a noticeable rise in serum 25-hydroxyvitamin D concentrations.

The higher prevalence of vitamin D deficiency among urban children, compared with their rural counterparts, can probably be attributed to higher outdoor physical activity in rural children, but also to environmental air pollution in urban settings, which can minimize the amount of UV light available to reach the skin. This latter can be especially true for Mexico City, which showed the highest prevalence of vitamin D deficiency among regions.

While in Mexico we do not have traditional clothing that could lead to reduced exposure to sunlight, we think that there could be some reasons for avoiding sun exposure in these children: (i) there is an increasing awareness of the risk of skin cancer, as well as increased marketing of sunscreen products aimed at children; (ii) it is likely children's use of indoor entertainment (videogames, computers, etc.) is reducing outdoor recreational activities; 
(iii) at least in some regions, social distress and insecurity could be a factor that minimizes outdoor activities as well.

In our study, milk was the main source of vitamin D in the diet. The current level of milk fortification with vitamin $D$ in Mexico has been established at $5 \mu \mathrm{g} / \mathrm{l}(200 \mathrm{IU} / \mathrm{l})^{(25)}$. We suggest that this level could be improved to warrant that most children fulfil the current recommendations. Other dairy products such as butter, margarine and cheese could also be subject to fortification as part of a government strategy to improve the vitamin D status in the population.

In summary, avoiding sun exposure, an indoor lifestyle, overweight, air pollution, scarce food sources of vitamin D and low supplement use are among the possible causal factors of the high prevalence of vitamin D deficiency and low 25-hydroxyvitamin D serum concentrations observed in Mexican children.

The strengths of the present study are the inclusion of a representative sample of Mexican pre-school and schoolage children, and training/standardization of the field personnel. Some of the constraints of the study are related to the limitations inherent to FFQ and misreporting of food intake by the caregiver, which could be related primarily to the child's age, gender and/or nutritional status. These may affect the estimate of the proportion of the population with suboptimal intakes ${ }^{(26)}$.

\section{Conclusion}

In conclusion, in this nationwide study in Mexican children, we found low vitamin D intakes and that milk is the main source of the vitamin. There is a high prevalence of vitamin D deficiency and it is associated with overweight in school-age children. Urgent actions are needed to fight this public health problem in Mexico.

\section{Acknowledgements}

Acknowledgements: The authors wish to thank Dr Ricardo Robledo, Head of Nutrition Laboratory at INSP, for his participation in the analysis of serum 25-hydroxyvitamin D. Financial support: This research project was funded by Danone de Mexico ${ }^{\circledR}$. The sponsor had no role in the study design, analysis, interpretation or publication of results. Conflict of interest: None. Authorship: A.F. was in charge of the statistical analysis and writing the manuscript; N.M., M.R. and S.V. made contributions to the manuscript; L.H.-B. contributed to the statistical analysis; M.F. designed the research, wrote the manuscript and had primary responsibility for the final content; A.C. contributed with the statistical analysis of the whole sample. All authors read and approved the final manuscript. Ethics of human subject participation: This study was conducted according to the guidelines laid down in the Declaration of Helsinki and all procedures involving human subjects/patients were approved by the Comité de Ética en Investigación of the INSP. Written informed consent was obtained from all mothers/caregivers of the children.

\section{Supplementary material}

To view supplementary material for this article, please visit https://doi.org/10.1017/S1368980017000040

\section{References}

1. Holick MF (2007) Vitamin D deficiency. N Engl J Med 357, 266-281.

2. Institute of Medicine (2011) Dietary Reference Intakes for Calcium and Vitamin D. Washington, DC: The National Academies Press.

3. Zhang R \& Naughton DP (2010) Vitamin D in health and disease: current perspectives. Nutr J 9, 65.

4. Hyppönen E (2010) Vitamin D and increasing incidence of type 1 diabetes - evidence for an association? Diabetes Obes Metab 12, 737-743.

5. Gupta A, Bush A, Hawrylowicz C et al. (2012) Vitamin D and asthma in children. Paediatr Respir Rev 13, 236-243.

6. Wacker M \& Holick MF (2013) Sunlight and vitamin D: A global perspective for health. Dermatoendocrinology 5, 51-108.

7. Holick MF \& Chen TC (2008) Vitamin D deficiency: a worldwide problem with health consequences. Am J Clin Nutr 87, issue 4, S1080-S1086.

8. Brito A, Cori H, Olivares M et al. (2013) Less than adequate vitamin D status and intake in Latin America and the Caribbean: a problem of unknown magnitude. Food Nutr Bull 34, 52-64.

9. Karalius VP, Zinn D, Wu J, Cao G et al. (2014) Prevalence of risk of deficiency and inadequacy of 25-hydroxyvitamin D in US children: NHANES 2003-2006. J Pediatr Endocrinol Metab 27, 461-466.

10. Au LE, Rogers GT, Harris SS et al. (2013) Associations of vitamin $\mathrm{D}$ intake with 25 -hydroxyvitamin $\mathrm{D}$ in overweight and racially/ethnically diverse US children. J Acad Nutr Diet 113, 1511-1516.

11. Flores M, Macias N, Lozada A et al. (2013) Serum 25-hydroxyvitamin D levels among Mexican children ages 2 y to 12 y: a national survey. Nutrition 29, 802-804.

12. Gutiérrez JP (2012) Encuesta Nacional de Salud y Nutrición 2012. Resultados Nacionales. Cuernavaca, México: Instituto Nacional de Salud Pública.

13. Rodríguez-Ramírez S, Mundo-Rosas V, Jiménez-Aguilar A et al. (2009) Methodology for the analysis of dietary data from the Mexican National Health and Nutrition Survey 2006. Salud Publica Mex 51, Suppl. 4, S523-S529.

14. Lohman T (1988) Anthropometric Standardization Reference Manual. Champaign, IL: Human Kinetics.

15. Habicht JP (1974) Estandarización de métodos epidemiológicos cuantitativos sobre el terreno (Standardization of anthropometric methods in the field). PAHO Bull 76, 375-384.

16. De Onis M (2006) WHO Child Growth Standards: Length/ Height-for-Age, Weight-for-Age, Weight-for-Length, Weightfor-Height and Body Mass Index-for-Age: Methods and Development. Geneva: WHO.

17. Freeman J, Wilson K, Spears R et al. (2015) Performance evaluation of four 25-hydroxyvitamin D assays to measure 25-hydroxyvitamin $\mathrm{D}_{2}$. Clin Biochem 48, 1097-1104.

18. Instituto Nacional de Salud Pública (2012) Bases de Datos del Valor Nutritivo de los Alimentos. Compilación del Instituto Nacional de Salud Pública. Cuernavaca, México: Instituto Nacional de Salud Pública. 
19. Heaney RP \& Holick MF (2011) Why the IOM recommendations for vitamin D are deficient. J Bone Miner Res 26, 455-457.

20. Holick MF (2009) Vitamin D status: measurement, interpretation and clinical application. Am J Epidemiol 19, 73-78.

21. Romero-Martínez M, Shamah-Levy T, Franco-Núñez A et al. (2013) National Health and Nutrition Survey 2012: design and coverage. Salud Publica Mex 55, Suppl. 2, S332-S340.

22. Lee SH, Kim SM, Park HS et al. (2013) Serum 25-hydroxyvitamin $\mathrm{D}$ levels, obesity and the metabolic syndrome among Korean children. Nutr Metab Cardiovasc Dis 23, 785-791.

23. Elizondo-Montemayor L, Ugalde-Casas PA, Serrano-González et al. (2009) Serum 25-hydroxyvitamin D concentration, life factors and obesity in Mexican children. Obesity (Silver Spring) 18, 1805-1811.

24. Mansbach JM, Ginde AA \& Camargo CA Jr (2009) Serum 25-hydroxyvitamin D levels among US children aged
1 to 11 years: do children need more vitamin D? Pediatrics 124, 1404-1410.

25. Diaro Oficial de la Federación (2010) NORMA Oficial Mexicana NOM-243-SSA1-2010, Productos y servicios. Leche, fórmula láctea, producto lácteo combinado y derivados lácteos. Disposiciones y especificaciones sanitarias. Métodos de prueba. http://dof.gob.mx/nota_detalle. php?'codigo $=5160755 \&$ fecha $=27 / 09 / 2010$ (accessed August 2016).

26. Flores M, Macías N, Rivera M et al. (2009) Energy and nutrient intake among Mexican school-aged children, Mexican National Health and Nutrition Survey 2006. Salud Publica Mex 51, Suppl. 4, S540-S550.

27. Instituto Nacional de Estadística y Geografía (2016) X Censo Nacional de Población y Vivienda 2010. Proyecciones de población 2010-2050 (CONAPO). http://www.inegi.org.mx/ est/contenidos/proyectos/ccpv/ (accessed September 2016). 